\title{
The Effect of Shoulder Stabilization Exercise through Visit Rehabilitation on Muscle Activity and Postural Alignment, Self-Efficacy in Rural Elderly People with Round Shoulders
}

\author{
Yong-Nam Kim', Jae-Woon Kim² \\ 'Department of Physical Therapy, Nambu University, Gwangju, Republic of Korea; ${ }^{2}$ Department of Physical Therapy, Chung-yeon Korean Medicine \\ Hospital, Gwangju, Republic of Korea
}

Purpose: This study covered the effect of shoulder stabilization exercise on muscle activity, postural alignment and self-efficacy of the elderly people with round shoulders by visiting village hall in rural area.

Methods: 40 elderly people with round shoulders were recruited for this study (experimental group: 20 subjects and control group: 20 subjects). The experimental group was asked to perform shoulder stabilization exercise 60 minutes per one time for 8 weeks and three times in a week and the control group was asked to receive education related to pain management for the initial one time. Before and after the experiment, we measured the subjects' muscle activity of upper trapezius, serratus anterior, infraspinatus, pectoralis major and the lower trapezius, then postural alignment of craniovertebral angle and round shoulder posture. In addition, self-efficacy is measured through the questionnaire.

Results: Compared to the control group, the experimental group showed significant differences in the muscle activity of all muscles, posture alignment of the craniovertebral angle. round shoulder posture, and improvement of self-efficacy.

Conclusion: We found that shoulder stabilization exercise is effective in muscle activity, postural alignment and self-efficacy of the elderly people through visit-rehabilitation service. This study can be used for improving the physical and mental abilities through active visit-rehabilitation service for areas where have poor medical benefits. It is considered that systematic visit rehabilitation service should have institutional framework ultimately.

Keywords: Shoulder stabilization exercise, Visit rehabilitation, Rural, Elderly, Round shoulder

\section{INTRODUCTION}

Round shoulder posture, RSP is one of the typical postural alignment that are abnormal and found in the upper body of the elderly people. This posture may cause pain in the neck, back, and shoulder, and is characterized by protraction and downward rotation of the scapula caused by lordosis and kyphosis of neck. ${ }^{1}$ If this posture persists for a long period of time, it may cause upper crossover syndrome, shortening of pectoralis major, pectoralis minor, levator scapulae and upper trapezius, weakening of the lower trapezius, serratus anterior and rhomboid, and feel pain in the head, temporomandibular joint, neck, thoracic, shoulder and arms. ${ }^{2}$ Because of the round shoulder posture, the upper cervical is extensively extension

Received May 18, 2021 Revised Jun 10, 2021

Accepted Jun 11, 2021

Corresponding author Jae-Woon Kim

E-mail kjwpt@naver.com and the lower cervical is extensively flexion, therefore the forward head position compared to the normal state of the head alignment and continuous kyphosis of the back bone is the biggest reason of causing the forward head position. ${ }^{3,4}$

Shoulder stabilization exercise, one of the representative exercise methods that can solve such problems of shoulder alignment is designed to make shoulder move smoothly in a neutral position, which increases the stability of the shoulder and restores the length and tension of the muscles around the shoulder normally. ${ }^{5}$

The elderly people living in rural areas do not often get a system for receiving health care services compared to the elderly people living in urban areas, and there are many difficulties in receiving treatment due to the

Copylight (C)2021 The Korean Society of Physical Therapy

This is an Open Access article distribute under the terms of the Creative Commons Attribution Non-commercial License (https:// creativecommons.org/license/by-nc/4.o.) which permits unrestricted non-commercial use, distribution, and reproduction in any medium, provided the original work is properly cited. 
lack of transportation facilities and the distance from various medical facilities, therefore their independence is lost caused by chronic pain and the quality of life is deteriorated. ${ }^{6}$ Self-efficacy refers to the ability of an individual successfully performing the actions necessary to achieve results, ${ }^{7}$ which is the greatest motive that makes the elderly people exercise or work. ${ }^{8}$ Self-efficacy is increased as much as regular exercise is conducted, and there was a close relationship between exercise and self-efficacy. ${ }^{9-13}$ In order to solve this problem, the support through phone calls or visiting is important. ${ }^{14}$ And this study is conducted through visit rehabilitation.

Visit rehabilitation minimizes pain and dysfunction by visiting areas or homes of patients who need long-term therapy and management and allows them to perform daily life independently, ${ }^{15}$ which is providing professional and systematic rehabilitation services to the elderly people and disabled people, thus it has an advantage that can bring various economic and social benefits by improving the quality of life. ${ }^{16}$ A preliminary study of visit rehabilitation showed that the daily life actions and physical functions were improved through visit rehabilitation service for the disabled people at home in the outskirts of the city, and it is reported that the patient's ability to take daily life action, motor function, ${ }^{17}$ and pain resistance was improved through continuous visit rehabilitation service. ${ }^{18}$

However, it is still lack of studies that covered rehabilitation through visit service to urban areas where it is difficult for people to receive medical services in Republic of Korea, and particularly, studies on people with central nervous system diseases such as stroke or the disabled characteristics are mostly covered while studies on musculoskeletal diseases are very scarce. Furthermore, there is currently no institutional basis for providing physical therapy services through visit service in Republic of Korea.

Therefore, this study aims at finding the effect of shoulder stabilization exercise for round shoulders on muscle activity, postural alignment, and self-efficacy of the elderly people through visit service to village hall in rural areas and provide the basic data to create a systematic framework for active rehabilitation service ultimately.

\section{METHODS}

\section{Subjects}

This study is conducted for the elderly people with round shoulders currently residing in rural areas of $\mathrm{N}$ city, Jeollanam-do, where medical services and traffic are poor compared to cities. A total of 40 subjects visited the town hall, and 20 subjects in the experiment group who conducted shoulder stabilization exercise and 20 subjects who conducted the pain
Table 1. General characteristic of subjects

\begin{tabular}{lccc}
\hline & $\begin{array}{c}\text { Experimental } \\
\text { group }\end{array}$ & $\begin{array}{c}\text { Control } \\
\text { group }\end{array}$ & $\mathrm{t}(\mathrm{p})$ \\
\hline Gender $(\mathrm{M} / \mathrm{f})$ & $10 / 10$ & $11 / 9$ & \\
Age $(\mathrm{yr})$ & $72.6 \pm 5.6$ & $73.3 \pm 6.2$ & $0.165(0.870)$ \\
Weight $(\mathrm{kg})$ & $65.0 \pm 8.7$ & $63.9 \pm 7.5$ & $0.630(0.630)$ \\
Height $(\mathrm{cm})$ & $163.6 \pm 8.4$ & $164.2 \pm 8.8$ & $0.091(0.944)$ \\
$\mathrm{BMI}^{\mathrm{b}}\left(\mathrm{kg} / \mathrm{m}^{2}\right)$ & $24.2 \pm 2.0$ & $23.6 \pm 1.6$ & $0.914(0.367)$ \\
\hline
\end{tabular}

Values are presented as mean \pm standard deviation, ashoulder stabilization exercise.

BMl: body mass index.

management training for the initial time, were randomly assigned to the experiment. For the study subjects, we selected those who agreed to participate in this study over 65 years, those who can communicate smoothly, and whose acromion's height can go up over $2.5 \mathrm{~cm}$ in the supine position, however, mentally disordered patients, people with cardiovascular risk and those who have disorders in sight and vestibular orders. The study also included a signed consent form, according to the ethical standards of the Declaration of Helsinki. The average age, weight, height, and BMI values of the experimental group and the control group are as follows (Table 1).

\section{Measurements}

\section{1) Muscle activity}

The surface electromyograph electrode is attached to the upper trapezius, serratus anterior, infraspinatus, pectoralis major, and lower trapezius. After attaching the electrode to the area to be measured, we normalized each muscle value into \%RVC and used reference voluntary contraction. For the upper trapezius, the sensor of supero-medial and infero-lateral to a point $2 \mathrm{~cm}$ lateral to one-half the distance between the $\mathrm{C} 7$ spinous process and the lateral tip of the acromion, ${ }^{19}$ For the serratus anterior, the sensor of over the seventh intercostal space, just anterior to the fibers of the latissimus dorsi ${ }^{20}$ For the infraspinatus, the sensor of below the scapular spine and at the middle of the IS fossa of the scapula, ${ }^{21}$ For the pectoralis major, the sensor of $3.5 \mathrm{~cm}$ medial to the anterior axillary line, ${ }^{19}$ For the lower trapezius, the sensor of $1 / 3$ between the spinous process of the seventh thoracic vertebrae and the medial border of the scapula at the intersection of the scapula spine. ${ }^{20}$ The EMG signals were sampled at 2,000 Hz with a gain of 1,000 and bandpass filtered at 20 to $450 \mathrm{~Hz}$.

The subjects kept their shoulders in a $90^{\circ}$ flexion state in a seated position, and repeated electromyograph signal in each muscle for 5 seconds then, the measured value was taken as the basic value of the reference voluntary contraction. The average value of 3 seconds was taken as a basic value for normalize it into \%RVC from the measured value. 
For the specific posture use a measure, we used as a measurement value for spontaneous standard contraction as same as the default posture, and additionally, the subjects were asked to hold a $0.5 \mathrm{~kg}$ dumbbell for $5 \mathrm{sec}-$ onds and 3 times. In order to prevent accumulating fatigue, they were allowed to have a break for 2 minutes between measurements, and the intermediate 3 seconds was taken as the average value to calculate the reference voluntary contraction.

\section{2) Postural alignment}

For the craniovertebral angle measurement, a mirror is placed in the front and the subjects were asked to put their arms comfortably next to the body, and look at their eyes, and after they continuously bended and stretched the head before measurement for 3 times. ${ }^{22}$ After taking a photograph, we used Image I program and calculated the craniovertebral angle.

In order to measure the round shoulder posture, we measured distance between the table floor and the rear part of the acromion. ${ }^{1}$ For accurate measurement, we measured the upper arm's rotation position at the same angle..$^{23}$

\section{3) Self- efficacy}

To measure self-efficacy, we used measurement tool developed by Sherer et al. ${ }^{24}$ This tool is consisted of 13 questions in the Likert-style with 5-point scale for 'Strongly Agree', 4 points for 'Agree', 3 points for 'Neutral', 2 points for 'Disagree' and 1 point for 'Strongly Disagree.' The higher score shows the better sense of self-efficacy.

\section{Procedure}

The experimental group visited the village hall and applied shoulder stabilization exercise for 60 minutes once, 3 times a week, and 8 weeks. The study method was conducting a total of five kinds of exercises. ${ }^{25}$ First, the subjects were asked to conduct 5 times of 3 sets with the rest of 5 seconds after keeping the posture for 20 seconds through scapula setting exercise in the prone position. Second, they were asked to conduct shoulder extension exercise in the prone position. Third, they conducted shoulder horizontal abduction exercise in the prone position. Fourth, they conducted shoulder external rotation exercise with the elbow joint flexion $90^{\circ}$ in the side-lying position. Fifth, they conducted shoulder external rotation exercise with both of the elbow joints $90^{\circ}$ flexion in the sitting position. For the second to fourth exercise, the elderly people exercised 10 times of 3 sets and rested 30 minutes between each set. During all interventions, they were asked to keep chin-in neck posture and not to throw strength to up- per trapezius. In the session, the strength of resistance was gradually increased within the range of painlessness. And when they felt pain in all exercises, the exercise was immediately stopped and re-executed after rest.

The elderly people in the control group received exercise and pain management education for an initial one time. For exercise and pain management education, the first 60 minutes of pain management and exercise were taught together and advised to do self-exercise at home. Pain management education explained self-stretching, and self-exercise explained muscle strengthening exercises using water bottles or thera-band, and joint range of motion improved exercises using sticks.

\section{Data analysis}

We analyzed data using SPSS 23.0 (SPSS, Chicago, IL, USA). The subjects' gen $\neg$ eral features showed detailed means and standard deviations by descriptive statistics. By using the Shapiro-Wilk test, we performed the normality tests. In order to find out the difference before and after the experiment in the group, we analyzed using a paired t-test. We conducted covariance analysis (ANCOVA) using the pre-experiment value as a covariate in order to correct the initial value difference before the experiment when comparing the differences between groups, and find out the difference between the two groups after the experiment. The statistical significance level was set at $\mathrm{p}<0.05$.

\section{RESULTS}

\section{Comparison of changes in shoulder muscle activity}

As a comparison of the change in shoulder muscle activity in the experimental group, we found significant differences in the upper trapezius, serratus anterior, infraspinatus, pectoralis major and the lower trapezius $(\mathrm{p}<0.05)$, and there were also significant differences in the upper trapezius and infraspinatus $(\mathrm{p}<0.05)$, however, there were no significant difference in muscle serratus anterior, pectoralis major and the lower trapezius ( $p>0.05)$. After the experiment, we found that there was a significant difference between the two groups in the upper trapezius, serratus anterior, infraspinatus, pectoralis major and the lower trapezius $(\mathrm{p}<0.05)$ (Table 2).

\section{Comparison of postural alignment changes}

As a comparison of the postural alignment changes in the experimental group, there was a significant difference in both the craniovertebral angle and the round shoulder posture $(\mathrm{p}<0.05)$, however, there was no significant difference in both the craniovertebral angle and the round shoulder 
Table 2. Comparison of the results of muscle activity within groups and between groups

\begin{tabular}{|c|c|c|c|}
\hline Muscle & Experimental group ${ }^{a}$ & Control group & $F(p)$ \\
\hline \multicolumn{4}{|c|}{ Upper trapezius (\%) } \\
\hline Pre & $171.29 \pm 11.63$ & $173.75 \pm 12.63$ & $33.840\left(<0.001^{+}\right)$ \\
\hline Post & $131.50 \pm 15.74$ & $161.21 \pm 19.11$ & \\
\hline$t(p)$ & $7.837\left(<0.001^{\star}\right)$ & $2.153\left(0.044^{\star}\right)$ & \\
\hline \multicolumn{4}{|c|}{ Serratus anterior (\%) } \\
\hline Pre & $115.15 \pm 6.88$ & $113.40 \pm 6.42$ & $78.967\left(<0.001^{+}\right)$ \\
\hline Post & $135.46 \pm 6.67$ & $111.92 \pm 9.65$ & \\
\hline$t(p)$ & $-8.349\left(<0.001^{\star}\right)$ & $0.577(0.571)$ & \\
\hline \multicolumn{4}{|c|}{ Infraspinatus (\%) } \\
\hline Pre & $129.60 \pm 9.90$ & $128.35 \pm 11.22$ & $44.102\left(<0.001^{+}\right)$ \\
\hline Post & $174.74 \pm 17.62$ & $137.07 \pm 18.87$ & \\
\hline$t(p)$ & $-11.246\left(<0.001^{\star}\right)$ & $-2.151\left(0.045^{\star}\right)$ & \\
\hline \multicolumn{4}{|c|}{ Pectoralis major (\%) } \\
\hline Pre & $120.10 \pm 11.81$ & $115.81 \pm 10.71$ & $9.391\left(0.004^{+}\right)$ \\
\hline Post & $106.88 \pm 4.78$ & $116.02 \pm 11.45$ & \\
\hline$t(p)$ & $4.312\left(<0.001^{*}\right)$ & $-0.055(0.957)$ & \\
\hline \multicolumn{4}{|c|}{ Lower trapezius (\%) } \\
\hline Pre & $119.15 \pm 9.95$ & $121.65 \pm 9.96$ & $73.646\left(<0.001^{+}\right)$ \\
\hline Post & $170.42 \pm 20.13$ & $120.18 \pm 16.32$ & \\
\hline$t(p)$ & $-10.160\left(<0.001^{\star}\right)$ & $0.379(0.709)$ & \\
\hline
\end{tabular}

Values are presented as mean \pm standard deviation, ashoulder stabilization exercise.

${ }^{*}$ significantly different within group by paired t-test.

$p<0.05$, significantly different each group by ANCOVA, $p<0.05$.

Table 3. Comparison of the results of postural alignment, self-efficacy within groups and between groups

\begin{tabular}{|c|c|c|c|}
\hline postural alignment & Experimental group ${ }^{a}$ & Control group & $F(p)$ \\
\hline \multicolumn{4}{|c|}{ Craniovetebral angle $\left({ }^{\circ}\right)$} \\
\hline Pre & $41.69 \pm 3.13$ & $41.68 \pm 2.92$ & $37.122\left(<0.001^{+}\right)$ \\
\hline Post & $44.28 \pm 3.17$ & $42.06 \pm 2.75$ & \\
\hline$t(p)$ & $-10.831\left(<0.001^{\star}\right)$ & $-1.329(0.200)$ & \\
\hline \multicolumn{4}{|c|}{ Round shoulder posture $(\mathrm{cm})$} \\
\hline Pre & $9.31 \pm 1.45$ & $9.18 \pm 1.20$ & $59.533\left(<0.001^{+}\right)$ \\
\hline Post & $7.22 \pm 1.11$ & $9.10 \pm 1.15$ & \\
\hline$t(p)$ & $9.490\left(<0.001^{\star}\right)$ & $0.414(0.683)$ & \\
\hline \multicolumn{4}{|l|}{ self-efficacy (score) } \\
\hline Pre & $1.94 \pm 0.45$ & $2.20 \pm 0.60$ & $102.406\left(<0.001^{+}\right)$ \\
\hline Post & $3.47 \pm 0.63$ & $2.26 \pm 0.73$ & \\
\hline$t(p)$ & $-12.232\left(<0.001^{\star}\right)$ & $-0.962(0.348)$ & \\
\hline
\end{tabular}

Values are presented as mean \pm standard deviation, ashoulder stabilization exercise. * significantly different within group by paired t-test.

$p<0.05$, ${ }^{+}$significantly different each group by ANCOVA, ${ }^{+} p<0.05$

posture in the control group $(\mathrm{p}>0.05)$. After the experiment, there was a significant difference between the two groups in both the craniovertebral angle and the round shoulder posture $(\mathrm{p}<0.05)$ (Table 3).

\section{Comparison of changes in self-efficacy}

There was a significant difference in comparison of changes in self-efficacy within the experimental group $(\mathrm{p}<0.05)$, however there was no signifi- cant difference in the control group ( $\mathrm{p}>0.05)$. After the experiment, there was a significant difference between the two groups $(\mathrm{p}<0.05)$ (Table 3).

\section{DISCUSSION}

This study indicates that how shoulder stabilization exercise affects muscle activity, postural alignment, and self-efficacy of the elderly people with 
round shoulders, and provides basic data for Korea's visit rehabilitation system. In response, this study classified the experimental group with applied shoulder stabilization exercises and the control group with applied initial pain management training to confirm changes in muscle activity, posture alignment, and self-efficacy after 8 weeks.

In the comparison within groups muscle activity in this study, experimental group was significant differences in all of the upper trapezius, serratus anterior, infraspinatus and pectoralis major, and control group was significant differences in the upper trapezius and infraspinatus, however, there were no significant differences in serratus anterior, pectoralis major and the lower trapezius. In the comparison between groups, the muscle activity of the upper trapezius and pectoralis major significantly decreased compared to the control group, and the muscle activity of muscle serratus anterior, infraspinatus and the lower trapezius significantly increased. Kang et al. ${ }^{26}$ compared the neck stabilization exercise group and the shoulder stabilization exercise group in 30 patients with forward head position, and as a result, the muscle activity of the upper trapezius in both groups significantly decreased, however the muscle activity of serratus anterior, infraspinatus and the lower trapezius significantly increased. It is reported that patients with shoulder pain have lower activity of muscle serratus anterior compared to normal adults, however, activity of the upper trapezius is high, ${ }^{27}$ which means that the activity of the upper trapezius is relatively extensive in order to compensate the application of serratus anterior, therefore the rotation of scapula becomes abnormal and shoulder joints may crash. ${ }^{28,29}$ In addition, Yun and Kang ${ }^{30}$ reported that 15 adults' muscle activity of the upper trapezius and pectoralis major has significantly decreased by conducting shoulder stabilization exercise, however the muscle activity of serratus anterior has significantly increased. This study is consistent with previous studies, and shoulder stabilization exercise decreased the muscle activity of the upper trapezius and pectoralis major, and increased the muscle activity of infraspinatus, serratus anterior and the lower trapezius and as a result, it improved upper cross syndrome. Through this improvement, it appears that the muscles around the shoulder may be combined more normally and worked smoothly.

As a result of comparing the posture alignment within the groups before and after the experiment in this study, we found significant differences in both the craniovertebral angle and the round shoulder posture in the experimental group, however, in the control group, there were no significant differences in both the craniovertebral angle and round shoulder postures. In the comparison between groups after the experiment, there were significant differences in both the craniovertebral angle and round shoulder posture of the experimental group compared to the control group. Go and Lee ${ }^{31}$ compared the shoulder stabilization exercise group and the general manual therapy group in 38 office workers, and after the intervention, both the forward head position and the round shoulder posture were improved in the shoulder stabilization exercise group. In addition, as a result of conducting shoulder stabilization exercise in 60 adults with forward head position and round shoulders, it is proven that the shoulder stabilization exercise group showed a significant difference in posture improvement compared to the general manual therapy group and the self-exercise group..$^{32}$ And, as a result of conducting shoulder stabilization exercise in 68 patients with shoulder impingement syndrome, both the forward head position and the round shoulder posture were improved compared to the general physical therapy group. ${ }^{33}$ As in previous studies, the shoulder stabilization exercise of this study normally restores the surrounding muscles acting as an imbalance caused by abnormal postural alignment, and it seems that the forward head position and the round shoulder posture have been significantly improved by direct posture guidance to exercise in the correct posture during the intervention.

As a result of comparing the self-efficacy of the pre- and post-test groups in this study, there was a significant difference in the experimental group, however there was no significant difference in the control group. And there was a significant difference in the comparison between groups after the experiment. Wada et al. ${ }^{34}$ reported that the self-efficacy was statistically significantly improved compared to the control group as a result of applying a customized exercise program to the elderly in the village hall. In addition, we conducted 6 weeks of exercise program and training for knee osteoarthritis patients, and it is found that self-efficacy showed significant difference after 3 months and 12 months. ${ }^{35}$ Self-efficacy is selfdiscipline and self-confidence, self-esteem, and satisfaction with life, so it can be seen that it has been enhanced by the training of this study. ${ }^{36}$ This study was also consistent with the results of previous studies, and this result seems to appear as each individual gets self-confidence in their bodies through visit rehabilitation service.

The limitation of this study lies on difficulty to find typicality as it is a study conducted on a village hall located in a specific area. In addition, it is difficult to generalize the results of patients with chronic musculoskeletal disorders since the study was conducted only on the elderly with round shoulders. Therefore, in the future, research should be conducted not in one area, but in several areas, and various and many studies should be conducted on various types of diseases.

In this study, 40 elderly people with round shoulders were divided into 
two groups of 20 people each, and we found that the group who visited the village hall and applied the shoulder stabilization exercise was more effective in shoulder muscle activity, postural alignment, and self-efficacy compared to the educational group receiving pain management for initial one-time. Therefore, this study is regarded as a good way to improve the quality of the elderly's daily life in the community through visit rehabilitation service. This has been shown to be an alternative to outpatient rehabilitation in that it provides systematic rehabilitation services to patients who are limited to visiting hospitals periodically. ${ }^{37,38}$

This study can be utilized to improve the quality of life through visit rehabilitation system based on areas with poor medical benefits, and as a result, it is considered that a systemic basis for visit rehabilitation system should be established.

\section{REFERENCES}

1. Sahrmann S, Azevedo DC, Dillen LV. Diagnosis and treatment of movement impairment syndromes. Braz J Physical Ther. 2017;21(6):391-9.

2. Harman K, Hubley-Kozey CL, Butler H. Effectiveness of an exercise program to improve forward head posture in normal adults: a randomized, controlled 10-week trial. J Man Manip Ther. 2005;13(3):163-76.

3. Kim JS, Choi JH, Lee MY. Effect of self-postural control with visual feedback in the foot pressures in the subject with forward head posture. J Kor Phys Ther. 2017;29(4):153-7.

4. Kong YS, Kim YM, Shim JM. Effects of modified cervical exercise on respiratory functions in smartphone users with forward head posture. J Kor Phys Ther. 2016;28(5):292-6.

5. Baskurt Z, Baskurt F, Gelecek N et al. The effectiveness of scapular stabilization exercise in the patients with subacromial impingement syndrome. J Back Musculoskelet Rehabil. 2011;24(3):173-9.

6. Kim YJ. The buffering effects of social supports on depression of the rural elderly. Jeonbuk University. Dissertation of Master's Degree. 2007.

7. Bandura A. Self-efficacy: toward a uniflying theory of behavioral change. Psychol Rev. 1977;84(2):191-215.

8. Forkan R, Pumper B, Smyth N et al. Exercise adherence following physical therapy intervention in older adults with impaired balance. Phys Ther. 2006;86(3):401-10.

9. Rhodes RE, Martin AD, Taunton JE. Temporal relationships of self-efficacy and social support as predictors of adherence in a 6-month strengthtraining program for older women. Percept Mot Skills. 2001;93(3):693703.

10. French DP, Olander EK, Chisholm A et al. Which behaviour change techniques are most effective at increasing older adults' self-efficacy and physical activity behaviour? a systematic review. Ann Behav Med. 2014; 48(2):225-34.

11. Bauman AE, Reis RS, Sallis JF et al. Correlates of physical activity: why are some people physically active and others not?. Lancet. 2012;380 (9838):258-71.

12. Rhodes RE, Pfaeffli LA. Mediators of physical activity behaviour change among adult non-clinical populations: a review update. Int J Behav Nutr Phys Act. 2010;7:37-48.

13. McAuley E, Jerome GJ, Elavsky S et al. Predicting long-term maintenance of physical activity in older adults. Prev Med. 2003;37(2):110-8.

14. Simek EM, McPhate L, Haines TP. Adherence to and efficacy of home exercise programs to prevent falls: a systematic review and meta-analysis of the impact of exercise program characteristics. Prev Med. 2012;55 (4):262-75.

15. Wolfe CD, Tilling K, Rudd AG. The effectiveness of community-based rehabilitation for stroke patients who remain at home: a pilot randomized trial. Clin Rehabil. 2000;14(6):563-9.

16. Park SK, Ji HY, Heo JW. Effects of home visiting physical therapy on activites of daily living and function in disabled persons living at home. J Kor Phys Ther. 2011;23(2):61-8.

17. Kwon CS, Kim SY, Jang HJ. The effects of home visiting physical therapy on the motor function, activity of daily living, and pain for disabled veterans. J Korean Soc Phys Med. 2014;9(2):171-9.

18. Hesse S, Staats M, Werner C et al. Ambulatory rehabilitation exercise for strike patients at home. preliminary results of scope, methods and effectiveness. Nervenarzt. 2001;72(12):950-4.

19. Boettcher CE, Ginn KA, Cathers I. Standard maximum isometric voluntary contraction tests for normalizing shoulder muscle EMG. J Orthop Res. 2008;26(12):1591-7.

20. Wochatz M, Rabe S, Wolter M et al. Reproducibility of scapular muscle activity in isokinetic shoulder flexion and extension. J Electromyogr Kinesiol. 2017;34:86-92.

21. Bitter NL, Clisby EF, Jones MA et al. Relative contributions of infraspinatus and deltoid during external rotation in healthy shoulders. J Shoulder Elbow Surg. 2007;16(5):563-8.

22. Diab AA, Moustafa IM. The efficacy of forward head correction on nerve root function and pain in cervical spondylotic radiculopathy: a randomized trial. Clin Rehabil. 2012;26(4):351-61.

23. Borstad JD. Resting position variables at the shoulder: evidence to support a posture-impairment association. Phys Ther. 2006;86(4):549-57.

24. Sherer M, Maddux JE, Meracn dnte B et al. The self-efficacy Scale: construction and validation. Psychol Rep. 1982;51(2):663-71.

25. Cools AM, Geerooms E, Van den Berghe DFM et al. Isokinetic scapular muscle performance in young elite gymnasts. J Athl Train. 2007;42(4): 458-63.

26. Kang JI, Choi HH, Jeong DK et al. Effect of scapular stabilization exercise on neck alignment and muscle activity in patients with forward head posture. J Phys Ther Sci. 2018;30(6):804-8.

27. Lin JJ. Functional activity characteristics of individuals with shoulder dysfunctions. J Electromyogr Kinesiol. 2005;15(6):576-86.

28. Cools AM, Witvrouw EE, Declercq GA et al. Scapular muscle recruitment patterns: trapezius muscle latency with and without impingement symptoms. Am J Sport Med. 2003;31(4):542-9.

29. Ludewig PM, Cook TM. Alterations in shoulder kinematics and associated muscle activity in people with symptoms of shoulder impingement. Phys Ther. 2000;80(3):276-91.

30. Yun SW, Kang JH. Effects of scapular dynamic stabilization exercise applying EMG biofeedback on upper trapezius, pectoralis major and serratus anterior activities. J Converg Inf Technol. 2017;7(4):159-64.

31. Go SU, Lee BH. Effects of scapular stability exercise on shoulder stability 
TRPT $\begin{aligned} & \text { The Journal of } \\ & \text { Korean Physical Therapy }\end{aligned}$

and rehabilitative ultrasound images in office workers. J Phys Ther Sci. 2016;28(11):2999-3002.

32. Fathollahnejad K, Letafatkar A, Hadadnezhad M. The effect of manual therapy and stabilizing exercises on forward head and rounded shoulder postures: a six-week intervention with a one-month follow-up study. BMC Musculoskelet Disord. 2019;20(1):86.

33. Moezy A, Sepehrifar S, Solaymani Dodaran M. The effects of scapular stabilization based exercise therapy on pain, posture, flexibility and shoulder mobility in patients with shoulder impingement syndrome: a controlled randomized clinical trial. Med J Islam Repub Iran. 2014; 28:87.

34. Wada T, Matsumoto H, Hagino H. Customized exercise programs implemented by physical therapists improve exercise-related self-efficacy and promote behavioral changes in elderly individuals without regular exercise: a randomized controlled trial. BMC Public Health. 2019;19(1):
917.

35. Jonsson T, Ekvall Hansson E, Thorstensson CA et al. The effect of education and supervised exercise on physical activity, pain, quality of life and self-efficacy an intervention study with a reference group. BMC Musculoskelet Disord. 2018;19(1):198.

36. Oliveira AL, Simoes A. A study of the impact of socio-demographic and psychological variables on the self-directedness of higher education students. Int J Self-Direct Learn. 2006;3(1):1-12.

37. Maltais F, Bourbeau J, Shapiro S et al. Effects of home-based pulmonary rehabilitation in patients with chronic obstructive pulmonary disease: a randomized trial. Ann Intern Med. 2008;149(12):869-78.

38. De Oliveira JCM, Leitao Filho FSS, Sampaio LMM et al. Outpatient vs. home-based pulmonary rehabilitation in COPD: a randomized controlled trial. Multi Discip Resp Med. 2010;5(6):401-8. 